\title{
Effect of test conditions on the temperature at which a protective debris bed is formed in fretting of a high strength steel
}

\author{
E.K Hayes, P.H. Shipway ${ }^{1}$ \\ Faculty of Engineering, \\ University of Nottingham, UK
}

\begin{abstract}
It is well known that mechanisms and rates of fretting wear of many metals are dependent upon the temperature of the environment; specifically, it is known that a transition temperature exists, above which the debris forms a protective bed in the contact which results in very low rates of wear being observed. This paper seeks to investigate the influence of contact geometry and slip amplitude on the transition temperature of a high strength alloy steel, and to understand these effects in terms of debris retention in (or expulsion from) the contact. Cylinder-on-flat fretting tests were performed at temperatures between $25^{\circ} \mathrm{C}$ and $250{ }^{\circ} \mathrm{C}$ with two displacement amplitudes $(25 \mu \mathrm{m}$ and 100 $\mu \mathrm{m})$ and two cylinder radii $(6 \mathrm{~mm}$ and $160 \mathrm{~mm})$. It was found that for the smaller cylinder radius, the transition temperature increased as the fretting displacement amplitude was increased. However, it was found that whilst the contacts with $6 \mathrm{~mm}$ radius cylinders and $160 \mathrm{~mm}$ radius cylinders exhibited very different mechanisms of wear at low temperature, the temperature at which the transition to forming of the protective debris bed was not strongly influenced by the contact geometry; moreover, at the higher temperature, the protective bed is formed irrespective of contact geometry. It is proposed that the reduction in wear rate at higher temperatures is associated with the retention of oxide debris within in the contact area for long enough that it sinters to form a protective 'glaze' layer. By increasing the displacement amplitude, the rate at which the oxide is ejected from the fretting contact increases and this reduces the ability to form a protective layer; as such, a higher temperature is required to form the protective glaze as the displacement amplitude is increased.
\end{abstract}

\section{INTRODUCTION}

It has long been known that sliding wear behaviour of metals is strongly influenced by the formation of oxide based debris, and the way that the debris either flows out of the contact [1] or forms compacted debris beds (sometimes known as glaze layers) within the contact $[2,3]$; the formation of compact oxide debris beds on a wearing surface is promoted by elevated temperatures and generally results in a significant reduction in the rates of wear. Fretting differs from sliding in that fretting is defined by small amplitude (often defined as less than $300 \mu \mathrm{m}$ [4]) oscillatory motion between the bodies in contact whereas in sliding the motion is of a much larger scale (and may even be unidirectional). Consequently, wear debris is more readily retained in the contact in fretting than it is in sliding, and thus its transformation to a protective glaze occurs more readily. Indeed, in recent work, Pearson et al. [5] reported that there was an $87 \%$ reduction in the rate of fretting wear of a high strength steel on increasing the temperature from $24{ }^{\circ} \mathrm{C}$ to just $85{ }^{\circ} \mathrm{C}$ (with very little further reduction as the temperature was raised further); they suggested that high temperatures resulted in an adhesive force between the oxide debris particles which inhibited their removal from the contact zone, and allowed them to be retained in the contact long enough for a stable load-bearing tribofilm to be created by particle sintering. This is in accord with other work [6-8] which suggests that the sintering to form a tribofilm occurs above a specific transition temperature. Whilst the transition temperatures appear to be low compared to those normally associated with particle sintering, the work of Zhou et al. [9] on the sintering behaviour of ultra-fine iron powders (not in the context of fretting) demonstrated that sintering of very fine $(40 \mathrm{~nm})$ iron particles can take place even at room temperature.

In addition to temperature, the macroscopic geometry of a fretting contact has been shown to influence the way in which the debris is formed and escapes from the contact. Fouvry et al. [10, 11] carried out tests with Ti-6Al-4V using a ball on flat configuration with varying ball diameters to cover a range of contact sizes and demonstrated that as the contact size increased, the coefficient of friction and the wear rate both decreased. In a similar vein, Warmuth et al. [12] carried out fretting wear experiments of high strength steel, which involved cylinder on flat specimens in which the cylinder radius was varied between $6 \mathrm{~mm}$ and $160 \mathrm{~mm}$ and the displacement amplitude was varied between $25 \mu \mathrm{m}$ and $100 \mu \mathrm{m}$. They observed that more conforming contact geometries (larger cylinder radii) were associated with lower rates of wear which led to subsurface deformation and adhesive transfer in the form of pitting and peaks rather than bulk material removal associated with fretting of less conforming contacts. They argued that the effects observed were not influenced by the changes in contact pressure associated with the different cylinder radii, but instead rationalised their

${ }^{1}$ Corresponding author: philip.shipway@nottingham.ac.uk 
observations both in terms of oxygen ingress into the contact during fretting and in terms of debris egress from the contact, with both of these being less favourable as the size of the contact increased (associated with increasing cylinder radius). However, they also suggested that the fretting displacement amplitude did not change the mechanisms of fretting wear.

It is evident that the retention of oxide-based debris within the contact is a key issue when considering the way in which temperature affects fretting behaviour. Whilst Pearson et al. [5] observed a particular transition temperature above which a protective glaze formed, it should be noted that they conducted experiments with only one contact geometry and at only one fretting amplitude. Given that the formation of the glaze-like debris bed is associated with the way that the debris is retained in the contact (and whether it is retained for long enough for sintering to take place), it is hypothesised that the transition to forming a stable debris bed will depend not only upon temperature, but also upon both the fretting amplitude and the contact geometry (as these will both also affect the debris egress); the validity of this hypothesis will be examined in this paper.

\section{EXPERIMENTAL METHOD}

\subsection{Materials and specimens}

\begin{tabular}{|l|l|l|l|l|}
\hline $\mathbf{C}$ & $\mathbf{S i}$ & $\mathbf{M n}$ & $\mathbf{P}$ & $\mathbf{S}$ \\
\hline $0.35-0.43$ & $0.1-0.35$ & $0.4-0.7$ & $<0.007$ & $<0.002$ \\
\hline $\mathrm{Cr}$ & $\mathrm{Mo}$ & $\mathrm{Ni}$ & $\mathrm{V}$ & $\mathrm{Fe}$ \\
\hline $3.0-3.5$ & $0.8-1.1$ & $<0.3$ & $0.15-0.25$ & Remainder \\
\hline Table 1 & \multicolumn{1}{|c|}{ Composition of high strength S132 steel (wt\%) } & \\
\hline
\end{tabular}

To allow direct comparison with previous work $[5,12,13]$, all the specimens were manufactured from a high strength steel (S132) which is commonly employed in aerospace applications where fretting of highly-loaded contacts may occur; the composition of this steel is given in Table 1. Initially, the material was cut into blanks and heat treated. The heat treatment consisted of a pre-heat to $940{ }^{\circ} \mathrm{C}$, at which the samples were held for 45 minutes and then quenched in oil. They were then tempered for 120 minutes at $570{ }^{\circ} \mathrm{C}$ and then cooled in air; the Vickers hardness (20 kgf applied load) of the samples following heat treatment were $465-477 \mathrm{kgf} \mathrm{mm}^{-2}$. Figure 1 shows the final dimensions of the samples after grinding where R may have the value of $6 \mathrm{~mm}$ or $160 \mathrm{~mm}$ (these values being selected as the largest and smallest employed in the work of Warmuth et al. [12]).

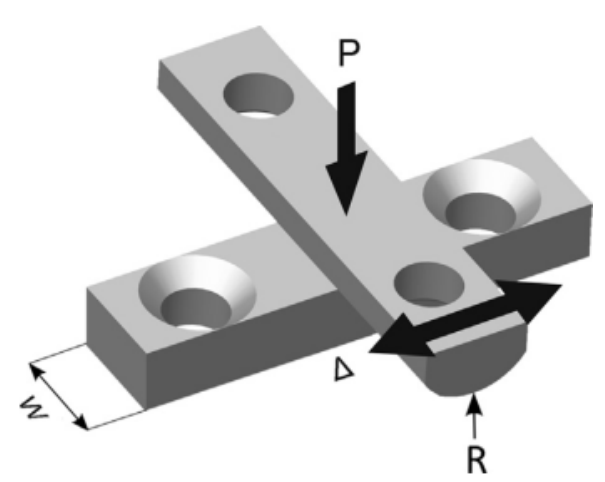

Figure 1 Diagram of the specimens and their positions in the fretting test. $W=10 \mathrm{~mm}, R=6 \mathrm{~mm} / 160 \mathrm{~mm}, P=$ normal load, $\Delta=$ applied displacement

\subsection{Fretting tests}

All tests were carried out using a cylinder on flat arrangement (as shown in Figure 1), with the general experimental setup for the fretting tests being shown in Figure 2. Before testing, all specimens were degreased with detergent and methylated spirit. The flat specimen was attached to the lower specimen mounting block (LSMB) and the cylindrical specimen was attached to the upper specimen mounting block (USMB) which is moved relative to the LSMB using an electromagnetic vibrator (EMV) which maintained a constant applied displacement amplitude $\left(\Delta^{*}\right)$ (see the idealised fretting loop in Figure 3 for definition of the displacement amplitude) with the displacements being measured with a capacitance displacement sensor. A constant normal load, $\mathrm{P}$, was applied to the USBM using a dead weight and lever arm. The tractional force, $Q$, was measured throughout each test using a piezoelectric load cell which is attached to the LSMB. Additionally, cartridge heaters on the USBM and the LSMB were utilised to heat the samples. Thermocouples 
were spot welded onto the surface of both the flat and cylindrical specimen and independent control loops ensured stability in temperature across the specimen pair. In all high temperature tests, the deviation between surface temperature and set temperature was relatively small $\left( \pm 2^{\circ} \mathrm{C}\right)$.

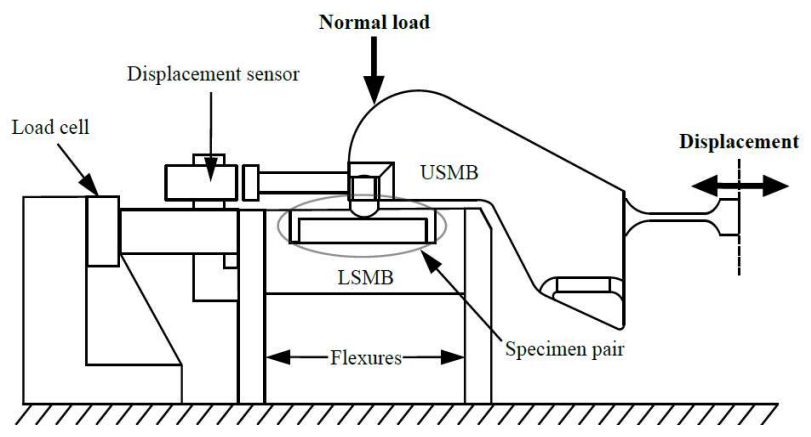

Figure 2 Schematic diagram of the fretting rig

Table 2 shows the fretting conditions that were used during testing, the temperatures being selected (based upon the experience of Pearson et al. [5]) to ensure that transitions from the low temperature (high wear) to the high temperature (low wear) would occur in all cases examined. The smaller applied displacement amplitude $\left(\Delta^{*}=25 \mu \mathrm{m}\right)$ was selected to mimic the work of Pearson et al. [5], whereas the higher value $\left(\Delta^{*}=100 \mu \mathrm{m}\right)$ was selected to allow the hypothesis to be tested within the range of normal gross-slip fretting.

During testing, both the load and displacement signals were recorded at a rate of 200 measurements per fretting cycle whilst the thermocouples were sampled at $1 \mathrm{~Hz}$. Post processing allowed the contact slip amplitude, $\delta$, and the maximum tangential force, $Q^{*}$, to be calculated for each fretting loop (see the idealised fretting loop in Figure 3 for definition of terms). The coefficient of friction (CoF) in each loop was defined as the ratio of $Q^{*}$ to $P$. For all tests conducted, loop shapes indicated that the contacts were in the gross sliding regime. For tests carried out $\Delta^{*}=25 \mu \mathrm{m}$, the typical slip

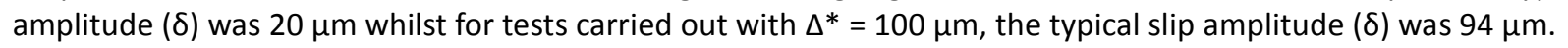

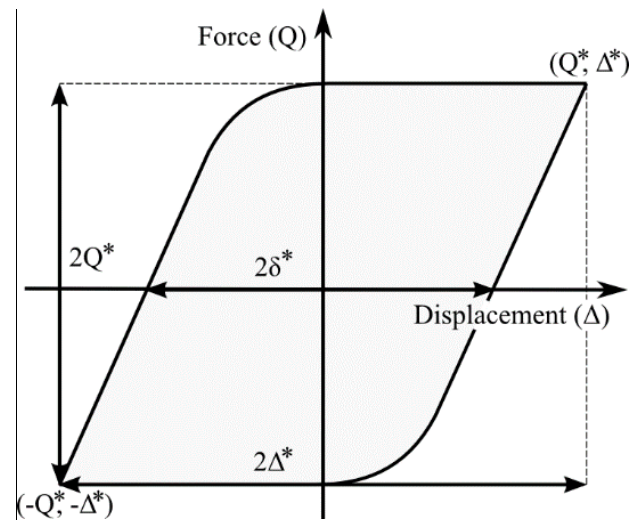

Figure 3 Gross sliding fretting loop

\begin{tabular}{llllll}
\hline $\begin{array}{l}\text { Normal load } \mathbf{P} \\
(\mathbf{N})\end{array}$ & $\begin{array}{l}\text { Applied displacement } \\
(\boldsymbol{\mu} \mathrm{m})\end{array}$ & $\begin{array}{l}\text { Duration } \\
(\text { cycles })\end{array}$ & $\begin{array}{l}\mathbf{N} \\
(\mathbf{H z})\end{array}$ & $\begin{array}{l}\text { Frequency } \\
\left({ }^{\circ} \mathbf{C}\right)\end{array}$ \\
\hline $\mathbf{2 5 0}$ & 25,100 & 100000 & 20 & $25,85,150,250$ \\
\hline Table 2 & Fretting Test Conditions & & &
\end{tabular}

\subsection{Characterization of wear and wear behaviour}

The allow the surface profile following wear testing to be examined, loose debris was first removed from the wear scar; the samples were lightly cleaned with industrial methylated spirit. The samples were then processed using a tactile profilometer (Taylor-Hobson Talysurf CLI 1000) in order to obtain the surface profile. Figure 4 shows the detail of how the flat specimens and cylindrical specimens were profiled. To estimate the wear volume and in turn, to facilitate 
calculation of the wear rate, a reference surface was defined for both the flat and cylindrical specimens. The reference surface for each case was the surface of the profile outside the wear scars extrapolated across the wear scar itself. Figure 5 represents how the wear volume is then characterized. Above the reference surface, any material transfer is defined as a positive volume $\mathrm{V}^{+}$in contrast to the material lost below the reference surface which has a negative volume $\mathrm{V}^{-}$. The net wear volume $\mathrm{V}^{\mathrm{w}}$ is then calculated as follows:

$V^{+}=V_{\text {Cylinder }}^{+}+V_{\text {Flat }}^{+} \quad$ (Equation 1a)

$V^{-}=V_{\text {Cylinder }}{ }^{-}+V_{\text {Flat }}{ }^{-} \quad$ (Equation 1b)

$V^{w}=-\left(V^{+}+V^{-}\right) \quad$ (Equation 1c)

As observed previously for specimen pairs of the same material of the same hardness [14], the volumes of worn material on the cylinder and flat specimens exhibited some differences, but these were generally within the range 1:2 to $2: 1$.

The wear rate and transfer rate were calculated based on the slip amplitude, $\delta$, and the number of cycles, $N$, and the applied load, $\mathrm{P}$, as shown in Equations 2 and 3;

Wear rate: $\dot{V}^{-}=\frac{V^{-}}{4 \delta P N} \quad$ (Equation 2)

Transfer rate: $\dot{V}^{+}=\frac{V^{+}}{4 \delta P N} \quad$ (Equation 3)

The confidence levels indicated in any figures (indicated as error bars) are a combination of the variability observed in repeat tests that were conducted in this work along with information regarding confidence levels indicated in the work of Pearson et al. [5] and Warmuth et al. [12] which both used the same experimental apparatus and test materials as were used in the current work.

Figure 4 Diagram of the surface profilometry scans
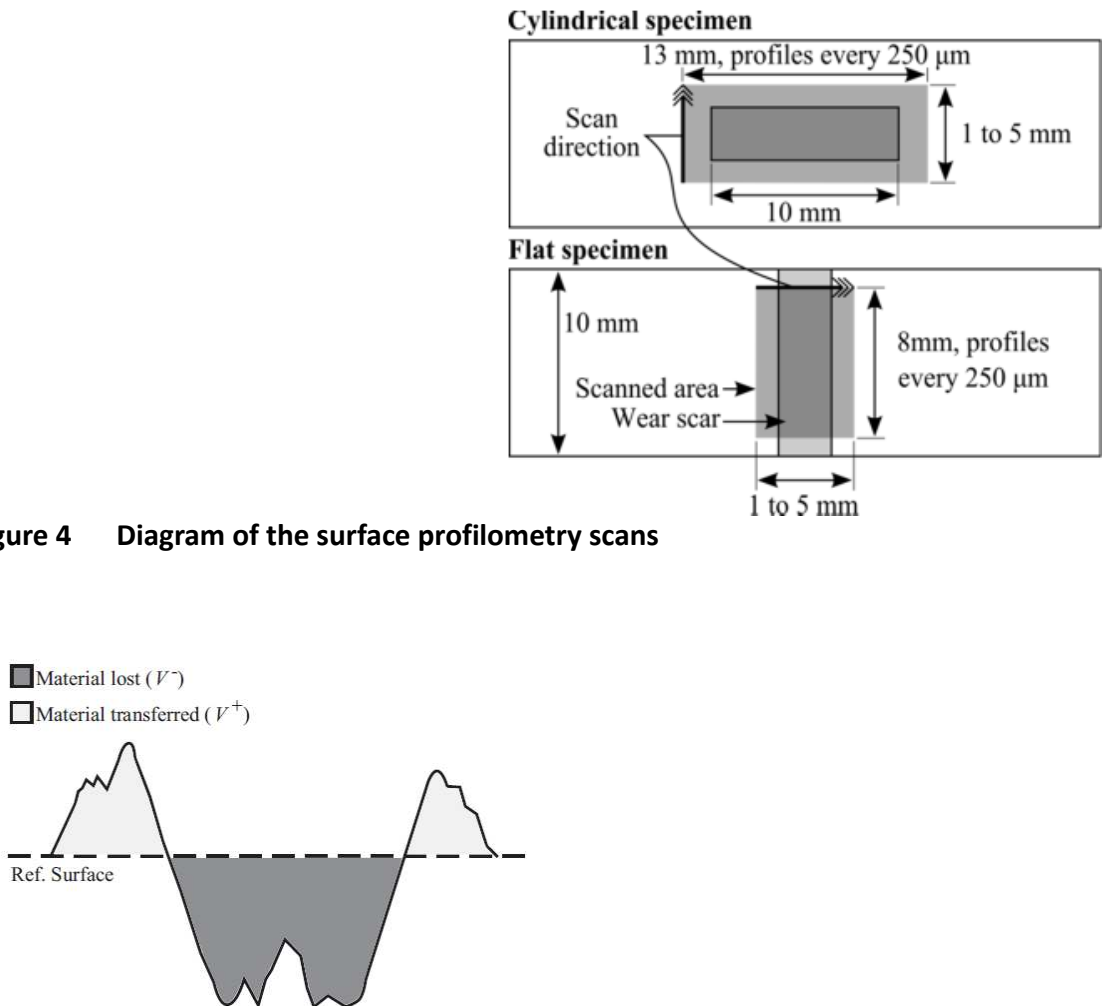
Back scattered electron (BSE) imaging in the scanning electron microscopy (SEM) was used in order to characterize the nature of the wear scars in terms of their material composition and surface morphology. In conditions where a glaze formed, it was generally observed on both specimen surfaces in the pair; the SEM images presented in this paper only relate to the flat specimen in each pair.

\section{RESULTS}

The relationship between wear rate and test temperature for tests with $6 \mathrm{~mm}$ radius cylindrical samples at displacement amplitude of $25 \mu \mathrm{m}$ and $100 \mu \mathrm{m}$ is shown in Figure 6 . In accord with previous work [5], it can be seen that for the $25 \mu \mathrm{m}$ tests, there is a significant reduction in wear rate when temperatures of $85^{\circ} \mathrm{C}$ are reached. However, it is evident that when the displacement amplitude was raised to $100 \mu \mathrm{m}$, no significant difference is observed in the wear rates at room temperature and at $85^{\circ} \mathrm{C}$, but that the significant reduction in wear is observed in this case when the temperature is further increased to $150{ }^{\circ} \mathrm{C}$. For both fretting displacement amplitudes examined, as the temperature is further increased above the transition temperature, the wear rate remains low.

Examples of the development of the CoF with number of cycles are presented in Figure 7a. It can be seen that in all three cases (representing both high and low rates of wear), there was a short initial transient, before relatively stable behaviour was observed with the CoF gradually falling as the tests proceeded. The initial transient was less than $5 \mathrm{k}$ cycles long in the two cases where the wear rate was low; however, a much longer initial transient of around $20 \mathrm{k}$ cycles was observed for the high wear case $\left(T=85^{\circ} \mathrm{C}, \Delta^{*}=100 \mu \mathrm{m}\right)$. Values of steady state coefficient of friction for the same set of tests for which the wear rate was presented in Figure 6 are presented in Figure 7bFigure 6 . At both displacement amplitudes, the coefficient of friction (and thus the energy dissipated per loop) is highest at temperatures below the transition temperature, and falls as the temperature is increased above the transition. At the highest temperature, the coefficient of friction remains high (at around 0.6) despite the wear rates being very low, indicating that the wear rate cannot readily be correlated with the frictional energy dissipated in the contact.

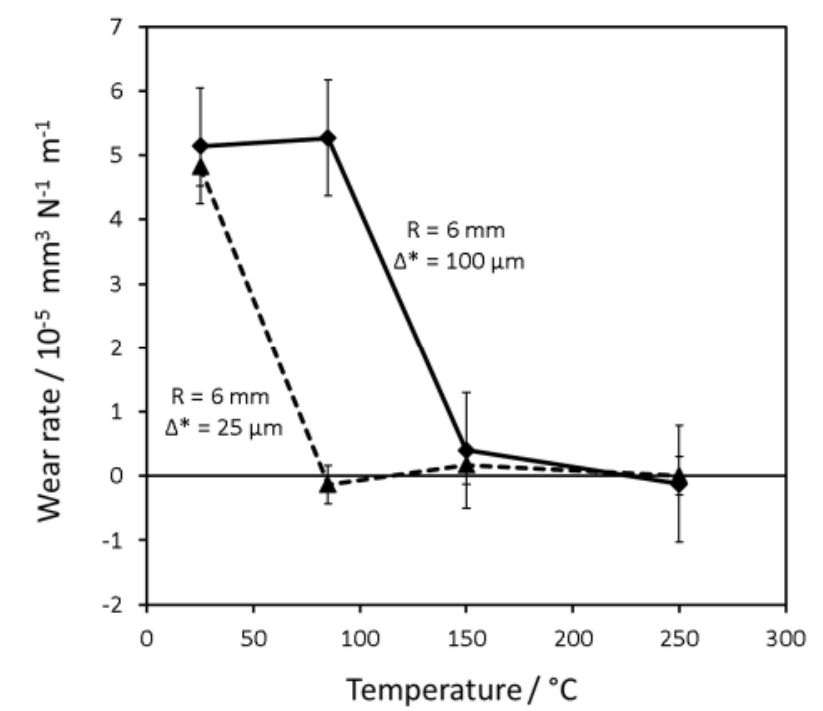

Figure 6 Dependence of wear rate on the temperature of fretting $\left(\Delta^{*}=25 \mu \mathrm{m}\right.$ and $\left.\Delta^{*}=100 \mu \mathrm{m} ; \mathrm{R}=6 \mathrm{~mm}\right)$ 

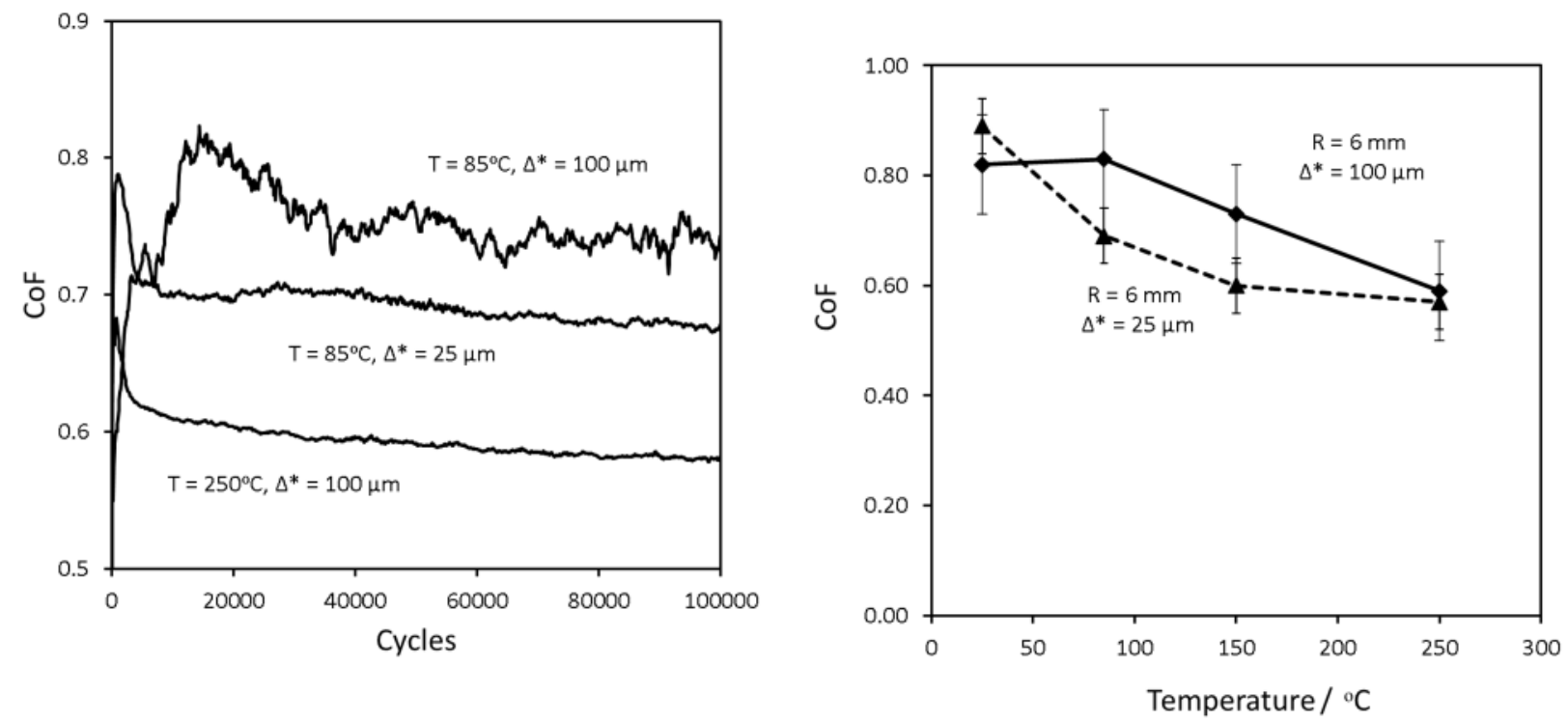

Figure 7 (a) Examples of development of CoF throughout a test for pairs with $R=6 \mathrm{~mm}$; (b) dependence of steady state CoF on the temperature of fretting for pairs with $R=6 \mathrm{~mm}$.

The relationships between wear rate and test temperature for tests with both $6 \mathrm{~mm}$ and $160 \mathrm{~mm}$ radius cylindrical specimens fretted at $\Delta^{*}=100 \mu \mathrm{m}$ are plotted in Figure 8 , where it can be seen that much lower rates of wear are observed for the tests with the larger cylinder radius of $160 \mathrm{~mm}$. Additionally it can be seen that the wear mechanism alters from one of negative wear rate to positive wear. This is associated with the fact that when an oxide builds up in the form of $\mathrm{Fe}_{2} \mathrm{O}_{3}$ and $\mathrm{Fe}_{3} \mathrm{O}_{4}$, they exhibit volumetric increases (the Pilling-Bedworth ratios for these oxides are both greater than two [15]). Figure 8 presents the overall wear rate from the pair, associated with loss of material from the contact; however, it must be noted that if fretting damage occurs by material simply transferring from member of the pair to the other, this will result in a wear rate of zero being recorded.

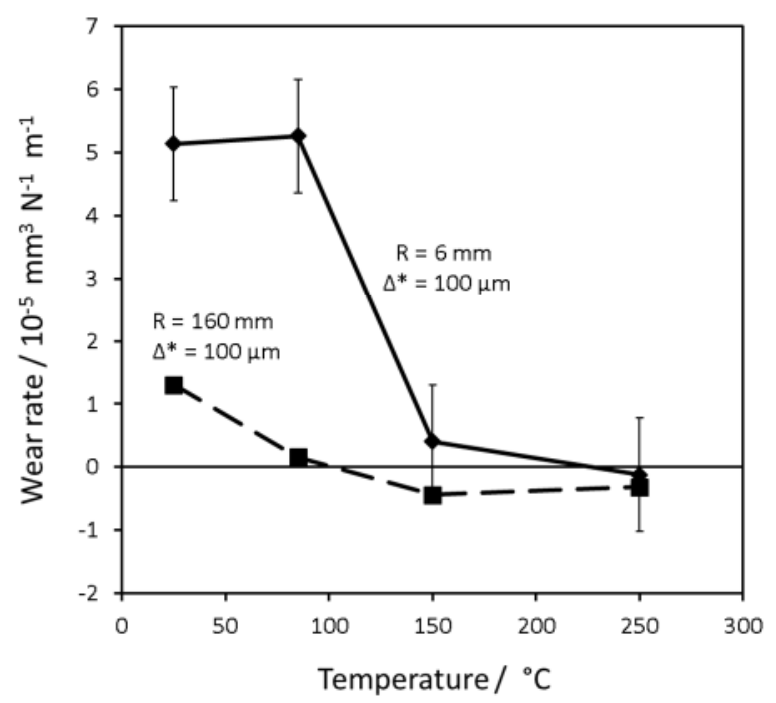

Figure 8 Relationship between wear rate and temperature of fretting for $6 \mathrm{~mm}$ and $160 \mathrm{~mm}$ specimen radius at $\Delta^{*}=100 \mu \mathrm{m}$.

Figure 9 shows the different morphologies of the flat specimens from the pairs following fretting at the higher applied displacement $\left(\Delta^{*}=100 \mu \mathrm{m}\right)$ as a function of temperature for tests with both the $6 \mathrm{~mm}$ and $160 \mathrm{~mm}$ radius cylinders. It should be noted that the 3-D profiles are at the same horizontal and vertical scale for each cylinder radius, but due to difference in the sizes of the scars and wear damage, the horizontal and vertical scale are different for the tests with 6 $\mathrm{mm}$ radius cylinders to those with the $160 \mathrm{~mm}$ radius cylinders. 
The tests with $6 \mathrm{~mm}$ radius cylinders display typical trough-like scar geometries whilst the tests with the $160 \mathrm{~mm}$ radius cylinders generally result in wear scars in the form of material transfer with pitting and peaks at the centre of the scars; rough regions that surround the pits and peaks are clearly visible on these latter wear scars. With the $6 \mathrm{~mm}$ radius cylinders, the reduction in wear volume that occurs between $85^{\circ} \mathrm{C}$ and $150^{\circ} \mathrm{C}$ is clearly visible, and by $250{ }^{\circ} \mathrm{C}$, the surface damage is very small. The width of the wear scar equally does not display any change between $25^{\circ} \mathrm{C}$ and $85{ }^{\circ} \mathrm{C}$; in contrast, a significant width reduction can be observed by $150^{\circ} \mathrm{C}$ and even more so by $250{ }^{\circ} \mathrm{C}$. In contrast, with $160 \mathrm{~mm}$ radius cylinders, the damage observed following fretting at the lower temperatures is in the form of subsurface deformation and adhesive transfer; however, this again has been eliminated by increases in the temperature to $250{ }^{\circ} \mathrm{C}$.

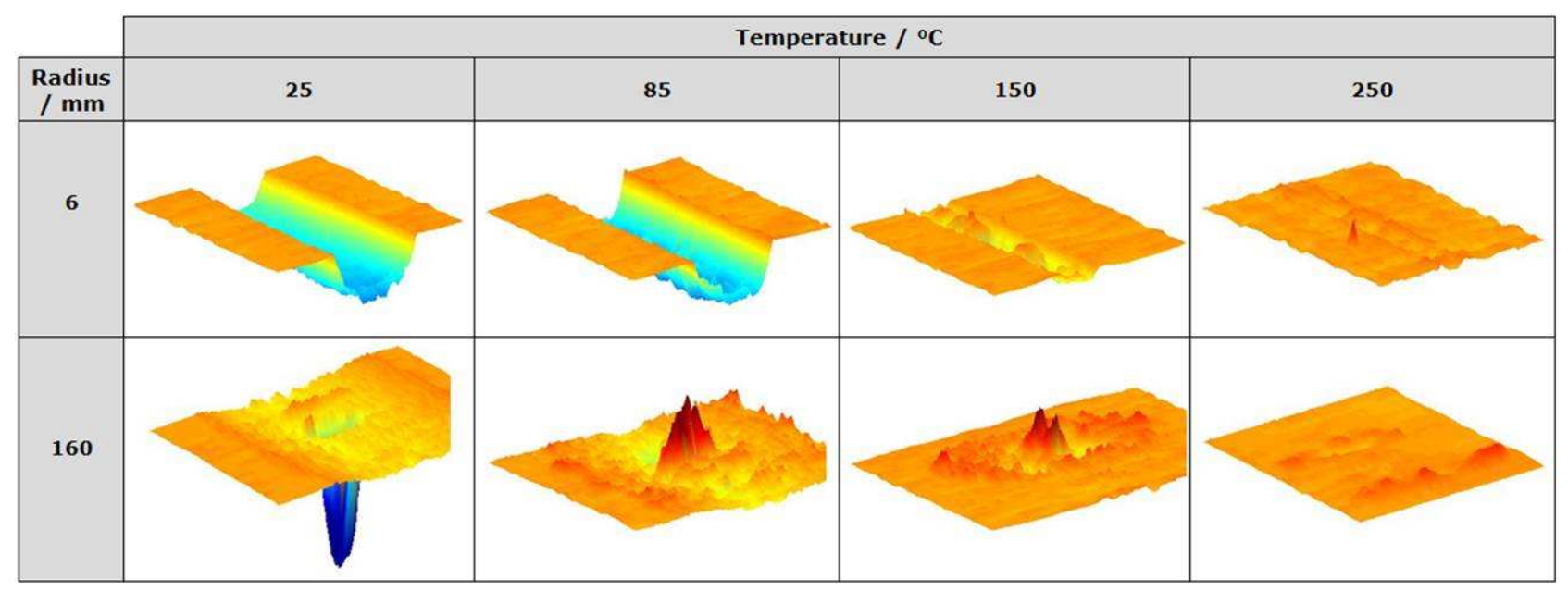

Figure 9 Map of surface topographies of the fretting wear scar on the flat specimen as a function of the radius of the cylindrical specimen and temperature at $\Delta^{*}=100 \mu \mathrm{m}$. Scars for same sample radii are at the same scale (horizontal and vertical). For $6 \mathrm{~mm}$ at $25^{\circ} \mathrm{C}$ : max trough depth is $25 \mu \mathrm{m}$, for $160 \mathrm{~mm}$ at $25^{\circ} \mathrm{C}$ : max pit depth is $12 \mu \mathrm{m}$.

SEM images of the wear scars following fretting tests (Figure 10 and Figure 11) provide further evidence regarding the mechanisms of wear and debris behaviour. Figure 10 displays surfaces of tests run with the $6 \mathrm{~mm}$ radius cylinders as a function of temperature and applied displacement amplitude. At the lower displacement amplitude $\left(\Delta^{*}\right)$ of $25 \mu \mathrm{m}, \mathrm{a}$ granular debris particle bed exists at $25^{\circ} \mathrm{C}$; the bed also exhibits numerous cracks which are indicative of the ease with which the bed is removed. However, by $85^{\circ} \mathrm{C}$, the debris bed with this lower displacement amplitude has a very different morphology; it is smooth with little evidence of its particulate nature, which indicates that this is now a glaze with sintering of the bed having occurred. As the temperature is further increased to $250{ }^{\circ} \mathrm{C}$, the oxide debris bed still has a smooth appearance, but it now appears to be thicker and have fuller coverage than the bed observed following fretting at $85^{\circ} \mathrm{C}$.

The behaviour at the two lower temperatures with the higher applied displacement amplitude of $100 \mu \mathrm{m}$ indicates that the debris bed forms less easily in this case than when $\Delta^{*}$ is $25 \mu \mathrm{m}$; in both cases, the oxide debris in the wear scar does not provide full coverage, with significant areas where there is exposed metallic material at the surface (brighter material in BSE imaging). At $85^{\circ} \mathrm{C}$, the patches of debris have changed from the rough, granular appearance that they had at room temperature to a smooth glaze (as observed at the lower displacement amplitude). Following tests at $250{ }^{\circ} \mathrm{C}$, the debris coverage is again complete, and takes the form of a smooth polished glaze layer with no exposed metal. 


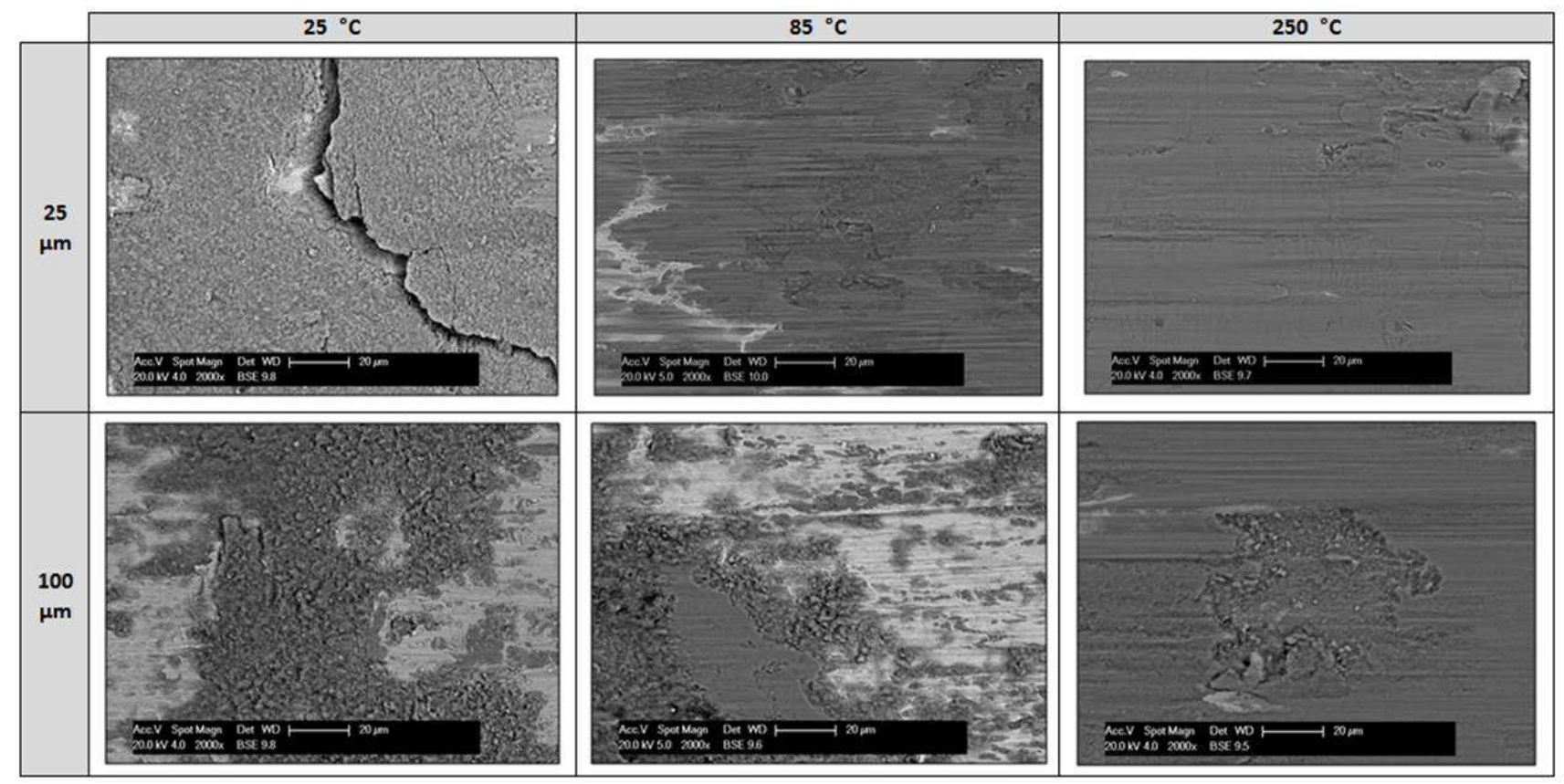

Figure 10 BSE SEM images of flat specimens following tests with $6 \mathrm{~mm}$ radius cylinders at three test temperatures for displacement amplitudes $\left(\Delta^{*}\right)$ of both $25 \mu \mathrm{m}$ and $100 \mu \mathrm{m}$.

In comparison, Figure 11 shows wear scars following tests with $160 \mathrm{~mm}$ radius cylinders at the higher applied displacement amplitude of $100 \mu \mathrm{m}$. At $25{ }^{\circ} \mathrm{C}$, the wear scar was made up of rough oxidized regions with large delaminated flakes of unstable oxide. Increasing the temperature to $85^{\circ} \mathrm{C}$ evidently promoted the formation of a glazelayer, although the debris bed is still clearly made up of particulate debris, and shows clear signs of fracture and damage of this layer; moreover, the debris bed does not show full coverage of the wear scar. By $250{ }^{\circ} \mathrm{C}$, the wear scar for tests conducted with the $160 \mathrm{~mm}$ radius cylinders exhibits the same appearance as that following tests with the $6 \mathrm{~mm}$ radius cylinders, namely a complete and smooth glaze-layer.

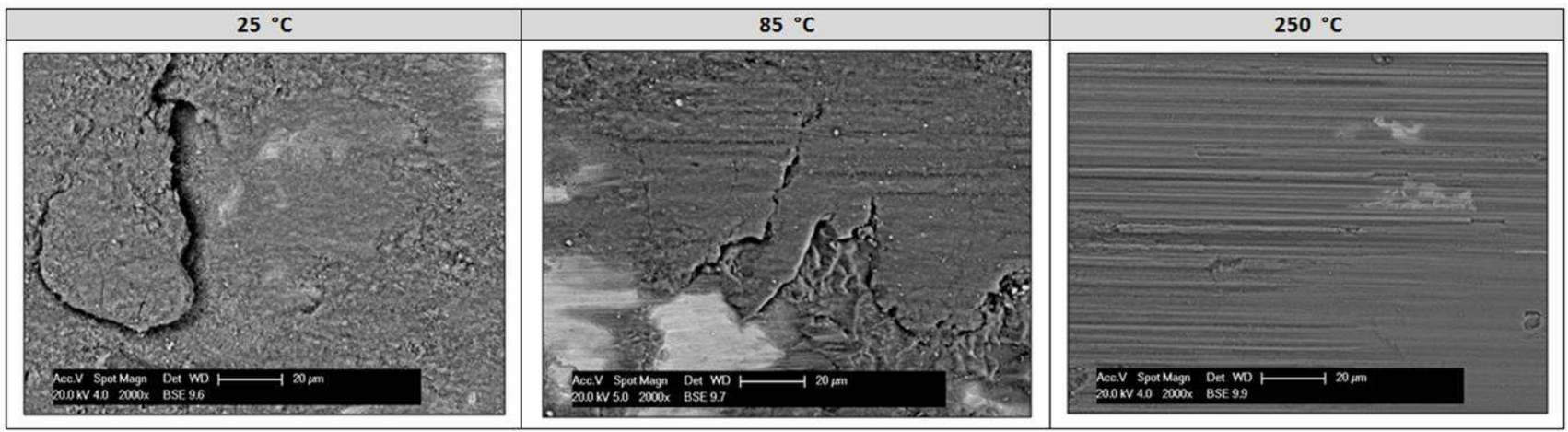

Figure 11 BSE SEM images of flat specimens following tests with $160 \mathrm{~mm}$ radius cylinders at three test temperatures for a displacement amplitude $\left(\Delta^{*}\right)$ of $100 \mu \mathrm{m}$.

\section{DISCUSSION}

\subsection{The role of fretting amplitude in the transition temperature}

In past work on fretting, different workers have observed transitions to a low rate of wear as the temperature is increased, but with different transition temperatures $[6,16]$. In considering these different transition temperatures, Pearson et al. [5] hypothesized that these differences were due to the different type of steels tested and their proneness to oxidation. However, Figure 6 demonstrates that the transition temperature is not only dependent upon the material type, but also on the displacement amplitude, with the transition temperature increasing as the displacement amplitude is increased. It is proposed that the higher fretting amplitude more effectively removes debris from the contact, and thus reduces the tendency for the debris to sinter in the contact to form a protective debris glaze layer. 
In addition, the effect that displacement amplitude can have on the oxide debris particle size may also play a significant role. Kato and Komai noted that sintering occurs more readily with smaller oxide particles in a rubbing contact [7]; in addition, Vaesson noted that increasing the fretting amplitude results in a significant increase in the particle size of the material transferred within the contact area [17]. As such, at larger displacement amplitudes, with larger debris particle size, the rate of sintering to form a protective bed would therefore be expected to be lower at a given temperature.

\subsection{The role of contact geometry in the transition temperature}

Previous work by Warmuth et al. [12] has indicated that the change in geometry of the contact (from a $6 \mathrm{~mm}$ radius cylinder to a $160 \mathrm{~mm}$ radius cylinder) results in significant changes in behaviour of the fretting contact. The larger radius cylinder can result in metal-metal contact and damage being observed, associated with the way that oxygen cannot readily penetrate the contact to oxidise nascent metal surfaces formed by the fretting action. However, if conditions were such that oxide debris did form, the larger wear scar width meant that the debris was less readily lost from the contact.

In the current work, Figure 8 shows that the wear rate at lower temperatures is much less with the $160 \mathrm{~mm}$ radius cylinders than it is with the $6 \mathrm{~mm}$ radius cylinders (due to geometric retention of the debris within the contact); this geometric retention of debris particles is again visible in Figure 11 where a thick but granular oxide bed is observed. Due to this geometric debris retention, the transition to a situation of retention of debris due to thermal sintering is less significant with the larger cylinder radius (Figure 8), although the change in mechanism itself is clear in the morphology of the debris, where the elevated temperature again results in formation of a sintered glaze (Figure 11). In addition, the increase in temperature also eliminates the formation of deep pits and peaks that were seen in the contact at the lower temperature (Figure 9); these exist due to regions of metal-metal contact prevailing on the fretting surfaces, and their elimination at the higher temperatures indicates that either oxygen ingress into the contact is made more efficient, or that the formation of oxides on these surfaces increases in rate such that the competition between oxide formation and its removal is now in favour of its formation and growth.

\section{CONCLUSION}

In fretting of metallic contacts, increases in temperature result in the formation a debris layer from the particulate wear debris which is in the form of a glaze which is smooth and well-sintered; the formation of a debris layer of this nature results in low rates of wear being observed. The debris needs to remain in the contact long enough for the sintering of the debris to take place, and the rate of sintering process will increase with temperature (with Arrhenius dependence). In this work, it has been shown that increases in the fretting amplitude promote expulsion of the oxide debris particles from the contact, and thus acts against the particles being able to sinter together to form a bed. In light of these opposing processes, it has been shown that the transition temperature for the formation of a debris bed in the form of a glaze increases as the fretting amplitude increases.

It is also known that the macroscopic shape of the fretting contact changes the way in which the debris is both formed and lost from the contact. The wear behaviours and mechanisms are very different at low temperatures for different geometries of contact. As the temperature is raised, the transition temperature for formation of a debris glaze is not observed to depend strongly on the macroscopic geometry; however, the differences observed at low temperatures diminish with increasing temperature, and by $250{ }^{\circ} \mathrm{C}$, the differences have been eliminated, with all contact types resulting in formation of a sintered glaze debris layer.

\section{REFERENCES}

[1] I. Iordanoff, Y. Berthier, S. Descartes, H. Heshmat, A review of recent approaches for modeling solid third bodies, Journal of Tribology, 124 (2002) 725 - 735.

[2] J. Jiang, F.H. Stott, M.M. Stack, The role of triboparticulates in dry sliding wear, Tribology International, 31 (1998) 245256.

[3] T.F.J. Quinn, Review of oxidational wear. Part I: The origins of oxidational wear, Tribology International, 16 (1983) $257-$ 271.

[4] O. Vingsbo, S. Soderberg, On fretting maps, Wear, 126 (1988) 131-147.

[5] S.R. Pearson, P.H. Shipway, J.O. Abere, R.A.A. Hewitt, The effect of temperature on wear and friction of a high strength steel in fretting, Wear, 303 (2013) 622-631.

[6] R. Rybiak, S. Fouvry, B. Bonnet, Fretting wear of stainless steels under variable temperature conditions: Introduction of a 'composite' wear law, Wear, 268 (2010) 413-423. 
[7] H. Kato, K. Komai, Tribofilm formation and mild wear by tribo-sintering of nanometer-sized oxide particles on rubbing steel surfaces, Wear, 262 (2007) 36-41.

[8] X. Jin, P.H. Shipway, W. Sun, The role of frictional power dissipation (as a function of frequency) and test temperature on contact temperature and the subsequent wear behaviour in a stainless steel contact in fretting, Wear, 330-331 (2015) 103-111.

[9] Y.H. Zhou, M. Harmelin, J. Bigot, Sintering behaviour of ultra-fine Fe, Ni and Fe-25wt\%Ni powders, Scripta Metallurgica, 23 (1989) 1391-1396.

[10] S. Fouvry, C. Paulin, S. Deyber, Impact of contact size and complex gross-partial slip conditions on Ti-6Al-4V/Ti-6Al4V fretting wear, Tribology International, 42 (2009) 461-474.

[11] R. Merhej, S. Fouvry, Contact size effect on fretting wear behaviour: Application to an AISI 52100/AISI 52100 interface, Lubrication Science, 21 (2009) 83-102.

[12] A.R. Warmuth, S.R. Pearson, P.H. Shipway, W. Sun, The effect of contact geometry on fretting wear rates and mechanisms for a high strength steel, Wear, 301 (2013) 491-500.

[13] A.R. Warmuth, P.H. Shipway, W. Sun, Fretting wear mapping: The influence of contact geometry and frequency on debris formation and ejection for a steel-on-steel pair, Proceedings of the Royal Society A: Mathematical, Physical and Engineering Sciences, 471 (2015).

[14] J.D. Lemm, A.R. Warmuth, S.R. Pearson, P.H. Shipway, The influence of surface hardness on the fretting wear of steel pairs-Its role in debris retention in the contact, Tribology International, 81 (2014) 258-266.

[15] N. Birks, G.H. Meier, F.S. Pettit, Introduction to the high temperature oxidation of metals, Cambridge University Press, 2006.

[16] T. Kayaba, A. Iwabuchi, The fretting wear of $0.45 \% \mathrm{C}$ steel and austenitic stainless steel from 20 to $650{ }^{\circ} \mathrm{C}$ in air, Wear, 74 (1981) 229-245.

[17] G.H.G. Vaessen, C.P.L. Commissaris, A.W.J. de Gee, Fretting Corrosion of Cu-Ni-Al against Plain Carbon Steel, Proceedings of the Institution of Mechanical Engineers, Conference Proceedings, 183 (1968) 125-128. 